\title{
The ideas of N. I. Vavilov and current problems of crop genetics
}

\section{Irina Anisimova and Evgeny Radchenko}

Federal Research Center N. I. Vavilov All-Russian Institute of Plant Genetic Resources, Bol'shaya Morskaya ul., 42-44, Saint Petersburg, 190000, Russian Federation

Address correspondence and requests for materials to Irina Anisimova, irina_anisimova@inbox.ru

\begin{abstract}
Some results of the studies of plant genetic resources held in the VIR Department of Genetics are discussed in light of N. I. Vavilov's theories of natural plant immunity, homologous series in hereditary variability, and interspecific hybridization. The long-term investigations resulted in identifying bread wheat, cultivated barley, oat, rye and sorghum accessions with new effective genes for resistance to diseases and pests. The large-scale immunological screening has revealed a narrow genetic diversity in wheat and barley for resistance to biotic and abiotic stressors. On the example of sunflowers, the significance of seed storage proteins for solving problems of domestication and introgressive hybridizations is demonstrated.
\end{abstract}

Keywords: N. I. Vavilov's laws, cultivated plants, genetic diversity, resistance to harmful organisms, economically valuable characters, genetic control, domestication, interspecific hybridization, seed proteins, comparative genomic approach.

\section{Introduction}

The research history of the Department of Genetics founded in VIR by Nikolai Ivanovich Vavilov in 1925 is closely connected with the history of the Institute and reflects global trends in the development of theoretical and applied genetics. From the first days after establishment, experimental work in the Department was focused on the knowledge of the hereditary variability of valuable characters and traits of cultivated plants and their wild relatives. In the 1930s the experimental work under the leadership of Dr. Georgii Dmitrievich Karpechenko was devoted to the problem of distant hybridization as a method for creating new forms of cultivated plants, the selective fertilization problem, and to developing new approaches for experimentally changing hereditary variation. Prior to World War II, research activities aimed at broadening the genetic diversity of cultivated plants were focused on the utilization of auto- and allopolyploidy, experimental mutagenesis, and distant hybridization. In the 1950s studies on the most promising areas of applied genetics were discontinued and eliminated in VIR. The revival began in the 1960s under the leadership of Trofim Yakovlevich Zarubaylo. Fortunately, the continuity of the development of genetic research was not lost, the scientific traditions were maintained, and the results of the latest achievements of modern genetics were successfully applied in experimental works. Comprehensive complex studies applying methods of genetics, physiology, biochemistry, biotechnology, molecular genetics, immunology, systematics and phylogenetics have become a characteristic feature of research in the field of crop genetics. The main research areas over the past 50 years have been studying the genetic basis of resistance to biotic and abiotic stressors, solving the problems of introgressive hybridization, elucidating the genetic control of valuable characters for breeding (such as resistance to biotic and abiotic stressors), and developing genetic col-
Citation: Anisimova, I. and Radchenko, E. 2020. The ideas of N. I. Vavilov and Bio. Comm, 65(1): 3-14. https://doi. Author's information: Irina Anisimova, Dr. of Sci. in Biology, Leading Researcher, orcid.org/0000-0003-0474-8860; Evgeny

Manuscript Editor: Anton Nizhnikov Department of Genetics and Biotechnology, Faculty of Biology, Saint Petersburg State Received: September 15, 2019:

Revised: October 15, 2019:

Copyright: (c) 2020 Anisimova and Radchenko. This is an open-access article distributed under the terms of the License Agreement with Saint Petersburg State University, which permits to the authors unrestricted distribution, and self-archiving free of charge.

Funding: This work was performed within the framework of state tasks \#0662-20190006 and \#0662-2019-0001.

Competing interests: The authors have declared that no competing interests exist. 
lections (Rigin, 2006). The present review summarizes some results obtained in the VIR's Department of Genetics during the last years.

\section{Crop genetic diversity for resistance to harmful organisms}

Immunological screening of plant genetic resources the search for genes and polygenic complexes responsible for plant resistance to harmful organisms - is an important area of work in the VIR Department of Genetics, the formation of which is most closely associated with the name of N. I. Vavilov. He created the doctrine of plant immunity, established the laws of natural immunity, laid the foundations of modern genetics of immunity, and developed theoretical aspects of breeding crops for resistance to diseases and pests.

The genetic control of plant resistance to diseases and pests is characterized by the interaction of two co-evolving systems. The interaction of pests with plants conforms the "gene for gene" relationships (Flor, 1971): each host resistance gene corresponds to a specific parasite virulence gene. A virulence mutation in a parasite causes a loss in the effectiveness of the host resistance gene. The ability of pests to adapt necessitates the ongoing search for new effective genes and genetic systems of resistance. A rational strategy for crop breeding for resistance to diseases and pests should include first of all the broadening of crop genetic diversity.

The significance of specialization and intraspecific differentiation of parasites was established by N. I. Vavilov in his final work, The Laws of Natural Plant Immunity to Infectious Diseases, presented at the meeting of the Biology Division of the USSR Academy of Sciences in 1940 and published posthumously in 1961. "The first and fundamental law which determines the existence of plant species and varieties resistant to a particular parasite, is specialization of parasites, their attachment to a specific range of hosts, species or genus of wild and cultivated plants. The phenomenon of specialization seems to be the major factor in the evolution of parasitism... The more a parasite is specialized on certain host genera and species, the more is probable the occurrence of immune forms within individual species" (Vavilov, 1964).

This situation, if we consider the resistance of cultivated plant varieties, can hardly be regarded at present as absolutely correct. For example, 3765 accessions of Triticum aestivum $\mathrm{L}$. from the VIR collection were studied for resistance to Puccinia triticina Erikss. (a highly specialized biotrophic pathogen), Parastagonospora nodorum (Berk.) Quaedvlieg, Verkley \& Crous. (a highly specialized hemibiotroph), and Cochliobolus sativus (S.Ito \& Kurib.) Drechsler ex Dastur (a broadly specialized hemibiotroph). However, in bread wheat a relationship be- tween the specialization of the parasite and the frequency of forms protected with their "own" resistance genes was not revealed. Among the assortment studied, 90 accessions were highly resistant to rust, but according to the results of hybridological, phytopathological, and molecular marker analyses all of them were protected by only four resistance genes, namely $\operatorname{Lr} 9, \operatorname{Lr} 19$, Lr24, and $\operatorname{Lr} 41$ (all are foreign in origin). Only one accession was resistant to leaf spotting and its resistance was expressed only under a low infectious load of the pathogen. Forms with high resistance to septoria and root rot were not detected at all. A similar situation was observed with the disease resistance of the cultivated barley Hordeum vulgare L. Out of 2365 collection accessions evaluated, only three were resistant to leaf rust (the causative agent is a highly specialized biotrophic pathogen), all of which are protected by the same $R p h 7$ gene, and only two accessions were resistant to C. sativus (the Rcs5 gene) (Tyryshkin, 2007).

At the same time, the regularity noted by N. I. Vavilov is quite distinctive when considering resistance of accessions of any species, rather than breeding varieties, which, in fact, Vavilov did, using mainly the term "form".

"The second fundamental law that determines the probability of occurrence of immune varieties and species within a particular crop is the presence or absence of a sharp genetic divergence... The most contrasting differences in immunity will distinguish the plants cytogenetically sharply differentiated to various species" (Vavilov, 1964). Discussing the hypothesis, N.I. Vavilov mentioned wheat, which has a large number of diverse botanical species with pronounced variation for disease resistance, and barley, representing a narrower genetic group with less pronounced differences.

Of the 4527 accessions of bread and durum wheat that were evaluated in various ecogeographical zones of the former USSR for their resistance to bird cherry-oat aphid (Rhopalosiphum padi L.) and English grain aphid (Sitobion avenae F.), only 48 weakly populated forms were revealed. A sufficiently high antibiosis (adverse effect of the plant on the insect during feeding) to the bird cherry-oat aphid was found in eight varieties of spring bread wheat. Due to the relative scarcity of resistant forms in the gene pools of T. aestivum and T.durum Desf. there is a necessity to study wild wheat species suitable for utilization in introgressive breeding. The experimental data have demonstrated a high diversity of the genus Triticum L. for resistance to S. avenae. The diploid species with the genomes $A^{u}$ (T. urartu Thum. Ex Gandilyan) and $\mathrm{A}^{\mathrm{b}}$ (T. boeoticum Boiss., T. monococcum L.) are the most resistant. The $\mathrm{D}$ genome can provide high resistance to species T. kiharae Dorof et Migush. and T. miguschovae Zhir. Pests overcome resistance conditioned by the G genome (Radchenko, 2011).

Wild relatives including Aegilops L. species are an important source of leaf rust resistance for T. aestivum. 
In a recent study by M. V. Kolesova and L. G. Tyryshkin (2018), the inheritance of effective juvenile leaf rust resistance was studied in six accessions of Ae. speltoides Tausch from the VIR collection and the resistance gene not identical to the Lr28, Lr35, Lr36 and Lr51 genes earlier introgressed into the T.aestivum genome from Ae. speltoides were identified.

Damage by the greenbug (Schizaphis graminum Rondani) of more than 5000 sorghum accessions belonging to four economic groups (grain, sugar, broom, sudangrass) from all centers of crop origin, as well as wild forms (110 samples) was assessed. Highly resistant accessions have been identified among the cultivated species (predominantly in grain sorghum and sudangrass). Fifteen insect resistance genes were identified, and ten of them turned out to be new, not previously employed in breeding. At the same time, differential interaction with the phytophage was not detected only for the accessions protected by the $\operatorname{Sgr} 7$ - Sgr11 genes, i.e., the need for a further search for sorghum genotypes possessing new resistance genes is quite obvious. It has also been shown that the gene pool of the genus is characterized by a wide distribution of weakly expressed resistance genes (Radchenko, 2000, 2006; Radchenko and Zubov, 2007).

Unfortunately, there is still no universally accepted classification of the genus Sorghum Moench. The taxonomy of the genus was subjected to an unprecedented revision, and different researchers identified from one to several dozen species. We cannot judge with confidence about the resistance of botanical species of the genus Sorghum due to the fact that the species affiliation of most of the studied forms is not defined. Accessions belonging to the species S.guineense Stapf, S. caffrorum Beauv., S. nigricans (Ruiz et Pav.) Snowd. were damaged to a greater extent. If we consider pest resistance by economic groups, then sugar sorghum is most severely damaged in the field, grain sorghum slightly less, followed by broom sorghum and sudangrass. At the same time, resistant accessions were found within each of these groups. It is known that all cultivated sorghum species are easily hybridized with each other. Their hybrids with wild species are usually fertile. Therefore, in our opinion, the search for a strong relation between botanical species and pest resistance does not make sense in this case. Unlike wheat, the analysis of wild forms showed the impossibility of resistance genes introgression (Radchenko, 2000).

"The third major law of plant immunity is a correlation between immune response to parasitic diseases and ecological type of a plant. ... The most contrasting variations for immunity can be revealed ... in the most contrasting environmental conditions" (Vavilov, 1964).

A relation between the ecological type of plants and resistance to English grain aphid was found in studies of rare wheat species. The population density on the ears of
T. dicoccum Schuebl. plants varied in a large range. European (subsp. Dicoccum) and Moroccan (subsp. maroccanum) emmer wheats were susceptible to aphids. Among the eastern (subsp. asiaticum) and Ethiopian (subsp. abyssinicum) emmer wheats the relatively weakly populated accessions originating from Armenia, Azerbaijan, Turkey, Ethiopia were identified. T. monococcum as a whole is resistant to S. avenae; however, a significant variation of the trait was noted among the accessions grown in Dagestan. Accessions belonging to the mountainous Western European and Mediterranean ecological groups were most heavily populated (Radchenko, 2011).

Ethiopian barleys are characterized by a huge diversity, many valuable biological and agronomic traits, including resistance to diseases. Studies were conducted on 925 Ethiopian barley accessions in laboratory experiments on the resistance to the northwest population of powdery mildew causal agent Blumeria graminis (DC.) Golovin ex Speer f. sp. hordei Marchal. Based on phenotypic screening, 27 pathogen-resistant accessions were selected and 47 forms were heterogeneous for the studied character. With the use of DNA markers, the 15 accessions were revealed which carried the mlo11 allele, ensuring the durable resistance of most modern barley varieties. The mildew resistance of the other 59 forms has been shown to be controlled by effective genes which are different from mlo11 (Abdullaev et al., 2019).

The genetic differentiation of potato species (genus Solanum L.) in terms of disease resistance is very prominent. Mexican potato species have been shown to possess the $R y_{\text {sto }}$ gene determining resistance to Potato Virus Y, while species from South America are protected by the $R y_{c h c}$ and $R y_{a d g}$ genes (Cockerham, 1970; Munoz et al., 1975; Zoteyeva et al., 2014).

According to N.I. Vavilov, “...immunity is developed through natural selection only in those conditions that promote the infection, and, as a rule, it is usually expressed only in the presence of a particular parasite on which the immunity is focused" (Vavilov, 1964). This statement slightly disaccords with a later interpretation that resistant forms can be found mainly in the centers of the crop origin. For example, sorghum forms that are most resistant to the greenbug were found among local accessions from China, and not from Africa (the primary center of the crop origin). Apparently, this is due to the long-standing relationship of the insect and the host plant. According to the famous aphidologist G. Kh. Shaposhnikov (1967), the probable center of the origin of most aphid groups is located in the mountainous areas of the Manchurian-Chinese and Indian subregions.

However, quite often, the centers of origin of the parasite and the host plant really coincide. This can be illustrated by the results of screening more than 150 accessions of wild tuber-bearing Solanum species under 
artificial inoculation with infection of Phytophthora infestans Mont. (de Bary), when the highest resistance was demonstrated for the Central American species (Zoteyeva et al., 2012). Among them the majority of highly resistant accessions belong to the species mostly distributed in Mexico, where the Toluca Valley is considered the center of diversity for $P$. infestans and is suggested to be the center of its origin (Fry et al., 1992).

Vavilov's fourth law of natural immunity was confirmed by our study as well: “... a group, or complex, immunity is a quite real fact widespread in nature" (Vavilov, 1964). T.monococcum accessions combining resistance to three aphid species - R.padi, S.avenae, and S. graminum - were identified (Radchenko, 2011). T. monococcum has complex resistance to wheat thrips, sunn pests, frit flies, sawflies, cereal leaf beetles, powdery mildew, smuts, rusts, and other harmful organisms. In the figurative expression of N.I. Vavilov, einkorns are "accumulators of complex immunity".

At the same time, cultivated einkorn is rather polymorphic, which, for example, was demonstrated in the studies of resistance to powdery mildew pathogen Blumeria graminis DC. f. sp. tritici Marchal (Lebedeva and Peusha, 2006). Using hybridological analysis and the test clone method, 102 accessions of T. monococcum have been studied and 70 forms proved to be resistant to the fungus. Most of these accessions originated from Albania, Bulgaria, Germany, and Turkey. A group of susceptible einkorn wheat plants included accessions from Azerbaijan, Armenia, Georgia, Spain, and (a few accessions) Germany. The results indicated that in most accessions resistance to the fungus population and clones was determined by dominant genes. In rare cases, resistance was determined by recessive genes or one, two, or three oligogenes. A group of einkorn wheat accessions has been found in which the resistance to powdery mildew was determined by the same dominant factor or different but closely linked ones.

Based on the abovementioned laws, N.I. Vavilov formulated the fifth and sixth laws. "Knowing the evolution of the crop, ... it can be largely predicted the location of immune forms important for a breeder" (Vavilov, 1964). "Ecological and geographical regularities in the expression of immunity can be relatively common, peculiar to various plants often related to different genera and even families. The development of susceptible or immune forms involves not only individual species or genera, but the whole groups whose evolution occurred in the same territory" (Vavilov, 1964). These laws are confirmed by the results obtained for barley and oat resistance.

Heterogeneous forms differing in the level of resistance to the Krasnodar greenbug population were found among 1358 barley accessions from East and South Asian countries. The high resistance of 98 accessions has been shown to be controlled by alleles not identical to alleles of the earlier identified Rsg1 gene. We assumed the possibility for localization of resistant genotypes in certain zones of China. To test this hypothesis, barley landrace accessions with known collection regions were systematized according to administration divisions (provinces) and natural zones of China. The resistant forms originated from the provinces Shaanxi, Shanxi, and Henan. Susceptible forms predominated among the accessions from the Tibet and Xinjiang-Uyghur autonomous regions. Shaanxi, Shanxi, and Henan provinces are located in the Central natural zone of China, which is characterized by a humid and very warm climate favorable for aphid development. The Tibet Autonomous Region is located in the Quinhai-Tibet and Sikan-Yunnan natural zones. The first zone is characterized by a cold, dry climate; height zonation of landscapes, from a hot zone in valleys where evergreen forests are widespread to a cold zone in the upper parts of mountains, is strongly expressed in the second. Evidently, there can be aphid reservoirs only in the Sikan-Yunnan natural zone. The Xinjiang-Uyghur Autonomous Region is a part of the Mongolian-Xinjiang natural zone characterized by a hot, dry summer and moderately cold winter, where dry steppe and desert landscapes predominate. With respect to climate conditions, the Xinjiang-Uyghur Autonomous Region is sufficiently favorable for aphid development, but to a far lesser degree than the Shaanxi, Shanxi, and Henan provinces (Radchenko et al., 2014).

Among 371 oat accessions from the collection of the N.I.Vavilov Institute of Plant Genetic Resources, mostly represented by landraces from Asia (Maritime Territory of Russian Federation, Mongolia, China, Japan, North Korea, India, Iran, Afghanistan, and Bhu$\tan ), 95$ were heterogeneous for resistance to the North Caucasus populations of the greenbug. Damage ratings of resistance in 47 accessions were high; a low level of resistance was identified in 48 genotypes. Higher frequency of greenbug-resistant accessions (60.5\%) was found among landraces from Mongolia. Lines with high expression of resistance were selected from seven landraces with a wide range of damage ratings. It is assumed that these lines are probably protected by earlier unknown genes of greenbug resistance (Radchenko et al., 2018).

A relatively simple genetic control of rye resistance to brown rust (P. recondita $\mathrm{f}$. sp. secalis) and stem rust (P.graminis f. sp. secalis) was revealed. In most cases, the sign of plant resistance to the fungal population is determined by one, less often two dominant genes. Rye resistance to brown rust is determined by at least seven dominant alleles of the $\operatorname{Lr} 4, \operatorname{Lr} 5, \operatorname{Lr} 6, \operatorname{Lr} 7, \operatorname{Lr} 8, \operatorname{Lr} 9$ and Lr10 genes, and to stem rust by at least two ( $\mathrm{Sr} 1$ and Sr2). Most of the identified rye oligogenes represent blocks of linked genes responsible for resistance to in- 
dividual clones of the fungus (Solodukhina, 2002). The dominance of the disease resistance trait facilitates the selection of breeding plants in the first hybrid generation, and the ability to transfer efficient genes in the process of breeding. Based on the identified sources of rye resistance to pathogens, as well as taking into account the laws of immunity genetics, 49 donors of effective disease resistance genes were created. The donors are characterized by maximum indices of positive economically valuable and a minimum number of negative traits. According to the results of retrospective and modern immunological analyses, rye has genetic mechanisms that ensure durable (for 30-80 years or more) resistance to brown and stem rust (Solodukhina, 2003).

Thus, immunological screening of cereal crops genetic resources and investigation of the peculiarities of interaction between pests and host plants indicate the undeniable relevance of all the positions of the "... evolutionary, or genetic in the broad sense, theory of natural immunity" (Vavilov, 1964). Moreover, the laws stated by N.I. Vavilov are also relevant for searching for genetic systems responsible for plant resistance to abiotic stressors. It is a well-known fact that genotypes resistant to toxic aluminium ions are usually found in regions with acid soils (Yakovleva, 2018).

The variability and inheritance of barley reaction to toxic aluminium ions was studied in the experiments of B. V. Rigin and O. V. Yakovleva. It was shown that the high tolerance of shoots in the variety Faust I is determined by one major tolerance factor and one dominant inhibitor gene, which hampers the manifestation of the dominant tolerance gene. The aluminium sensitivity of roots and seven-day shoots of cv. Faust I is determined by different genetic factors (Rigin and Yakovleva, 2006).

Considering the problem of immunity in all its diversity, Nikolai Ivanovich attached great importance to the practical orientation of his research. A century ago, young N. I. Vavilov wrote: "The creation of cereal varieties that are resistant to fungal diseases is one of the immediate tasks of modern breeding of agricultural plants. The first step towards solving this problem is a detailed study of existing cereal forms in relation to parasitic fungi" (Vavilov, 1913). The relevance of this problem today has only increased many times over. Discussing the problems of breeding varieties for resistance to harmful organisms, N.I. Vavilov pointed out the rarity of resistant forms among cereal accessions, emphasized the enormous importance of related species in creating immune forms of cultivated plants, and noted the possibility and necessity of using mutagenesis in breeding for resistance.

The stock of effective resistance genes can be increased not only by screening the collection accessions, but also by introgressing resistance from wild relatives. The narrowness of the genetic diversity of wheat and barley for high effective resistance to diseases and pests, as well as the low frequency of resistant forms among close relatives, necessitates the development of additional methods for its broadening - in particular, the induction of somaclonal variation (Tyryshkin and Shevchenko, 1994). More than 1500 descendants of regenerants derived from immature embryo callus cultures of the barley variety Golden Promise were examined. Among them three families were less damaged by the Krasnodar greenbug population than the original variety. Ten families of descendants of the wheat variety Orofen expressed low resistance to S. graminum. The insects did not prefer those plants for nutrition but negatively affected their development. A polygenic control of this resistance was assumed (Radchenko and Tyryshkin, 2004).

Genetic studies have shown that the number of genes conditioning a high level of resistance expression is extremely small in cultivated plants, which indicates the urgent need for broadening genetic diversity for effective resistance. Depending on the crop characteristics, the specific significance of a particular method of increasing diversity may be different. Introgressive hybridization can be effective for wheat, whereas the search for resistant forms within cultivated species can be promising for sorghum. Mutagenesis and genetic engineering methods gain primary importance in the case of depletion of the gene pool.

An extremely small number of effective pest resistance genes also necessitates the development of approaches to extend their useful life, such as the creation of multilinear varieties, gene pyramiding, combining the main and small resistance genes in one genotype, etc. The process of adaptation of pests to resistant varieties can also be slowed by the appropriate territorial distribution of donors with different resistance genes. This approach requires knowledge of the genetic structure of the pathogen and pest populations, their variability, and the relationship of different populations with each other.

A study of the intraspecific variability in S. graminum has revealed a relative isolation of European populations of the aphid from Asian ones. The experiments suggest the important role of migration in determining insect population structure. Recent studies have also demonstrated significant seasonal variability in the genetic structure of the Krasnodar aphid population. Therefore, a longstanding investigation of the variability of insect populations for virulence to the sorghum host plant is necessary in order to offer a rational layout of varieties and hybrids carrying different resistance genes. Nevertheless, the creation of an "irregular," that is, an unregulated mosaic of varieties, is quite possible at the present time.

In the post-genomic era, studies assessing the genetic variability of crop species and elucidating the genetic determination of resistance to biotic and abiotic stresses, 
pollen fertility restoration trait, photoperiodic response and other economically valuable characters acquired a new impulse. In fact, the current studies carried out in the Department of Genetics in a close collaboration with the Departments of Biochemistry and Molecular Biology, Plant Physiology, Biotechnology, and with the Departments of Plant Genetic Resources have a multidisciplinary character. For example, using genetic and physiological approaches, B. V. Rigin and co-workers selected a number of fast-developing highly productive lines of T. aestivum (Rigin et al., 2018). Together with conventional methods of genetic analysis, molecular techniques are currently an integral part of the research work in the VIR Department of Genetics. Molecular marker techniques facilitated a more efficient work with collections of plant genetic resources. Molecular screening of accession collections of cereal (wheat, barley, sorghum) and oil (sunflower) crops is currently an integral part of plant genetic variability studies (Tyryshkin et al., 2006; Anisimova et al., 2011; Abdullaev et al., 2017, 2019).

\section{Sunflower seed proteins as domestication-associated characters}

Resistance to biotic and abiotic stressors, as well as the ability to produce storage substances, are among the key characters of cultivated plants that play a strategic role in ensuring food security in human societies. Many plants are cultivated solely for seeds used as food sources. Storage proteins are the main biochemical compounds of plant seeds (Shewry et al., 1995). They accumulate in abundance during seed development and serve as sources of carbon, nitrogen and sulfur for a germinating embryo and a developing seedling. The distinctive features of seed proteins are the lack of catalytic function, the high content of glutamic and aspartic acid residues, and the localization in membrane-bound vacuoles called protein bodies. Seed proteins are extremely valuable components in human nutrition and animal feeding. They are widely used as raw materials for the food industry. Therefore, seed proteins have been the subject of numerous studies over the past decades. Genetic polymorphism of seed proteins is especially significant in some cereal species (for example, wheat and barley). Seed storage proteins are successfully used as genetic markers both in theoretical and applied studies of plant genetic resources, and in the breeding process and seed production (Konarev, 2006). Moreover, the high level of biosynthesis in developing seeds, as well as tissue specificity, determined the choice of storage proteins as an attractive system for studying molecular mechanisms of gene expression. Extensive information is available on the composition and variability of the storage proteins of cereal seeds. Among the dicotyledonous plants, the proteins of legumes, cruciferous vegetables, and a num- ber of oil plants (cotton, sunflower, castor oil plants) were studied more thoroughly. Data on the composition of seed proteins of many other species that do not have practical importance are still missing or very limited.

Seed characters and hence their biochemical composition have been subjected to primary selection during the domestication of plants. N. I. Vavilov played a decisive role in developing the theory of the origin of cultivated plants. He considered the areas where domestication took place as primary centers (foci) of origin and genetic diversity, while he considered secondary areas in which the diversity of new forms was associated with the further distribution of cultivated and primitive forms and subsequent selection (Vavilov, 1987). Domestication has led to significant changes in plant appearance. Parts used by humans are characterized by the greatest diversification in cultivated plants. These changes were termed as "domestication syndrome" (Goncharov, 2013).

The cultivated sunflower, Helianthus annuus L, is a classic example of domestication syndrome. As in many other crops, the process of sunflower domestication was accompanied by an increase in the size of the inflorescences and seed weight and a reduction of the dormancy period. The morphotype of the cultivated sunflower is a single-headed plant with large seeds that do not disperse by shattering, while its wild ancestors are highly branched, have small seeds that are shed upon ripening, and have a long dormancy period. Flowering time in the cultivated sunflower starts much earlier than in wild annual species, and seed biochemical composition differs significantly, primarily due to the increased oil content and varying fatty acid composition (Gavrilova and Anisimova, 2003; Radanović et al., 2018).

The sunflower is a valuable food and industrial crop. Sunflower plants are used in medicine and in manufacturing dyes, and are also considered a promising source for biofuel production. Like many other plants, selection and introgressive hybridization played a decisive role in the evolution of the cultivated sunflower. The first domesticated sunflower forms were brought by naturalists to Europe at the beginning of the 16th century, where further development of the crop took place until the 19th century (Gavrilova and Anisimova, 2017). The search for genes that served as targets for domestication and subsequent selection, as well as introgressed genes, is very relevant for elucidating sunflower evolutionary history. Based on comparative sequence characterization, genes involved in the determination of flowering time, seed germination, plant growth/development, and branching and QTLs were identified as candidates for positive selection during either domestication or improvement of the sunflower (Mandel et al., 2014). A genomic scan of modern varieties, landraces, and annual wild species made it possible to isolate molecular targets for domestication and improving selection (Chapman et 
al., 2008; Baute et al., 2013). The nucleotide sequence of one of these targets, the precursor gene of the seed $11 \mathrm{~S}$ seed globulin, was almost identical in modern improved varieties; polymorphic variants were observed in primitive forms and a higher polymorphism was observed in wild species of the genus Helianthus L. (Chapman et al., 2008).

The salt-soluble protein $11 \mathrm{~S}$ globulin (helianthinin) and water-soluble $2 \mathrm{~S}$ albumins are the main components of protein fraction in sunflower seed. The content of helianthinin in the protein fraction of sunflower seed constitutes approximately $60 \% .11 \mathrm{~S}$ globulin is the main component of sunflower protein isolates, widely used in the food industry. The products of hydrolysis of helianthinin by digestive enzymes have antihypertensive properties due to their ability to inhibit angiotensin-converting enzyme (Megias et al., 2009).

Helianthinin is an oligomeric protein having a molecular weight of about $305 \mathrm{kDa}$ and consisting of six spherical subunits. Each subunit is formed by acidic ( $\alpha)$ and basic $(\beta)$ polypeptides bound by disulfide bonds. Up to six types of subunits and polypeptides were identified that differ in charge and molecular weight (Anisimova and Gavrilyuk, 1989). The subunits are classified into three types, A, B and C, depending on their molecular weight.

We characterized helianthinin polymorphism in a sample set of more than 30,000 sunflower genotypes of different origin. The improved varieties, except for silage cultivar Giant 549, are characterized by identical electrophoretic patterns of helianthinin, while certain lines of the sunflower genetic collection often possess genotype-specific electrophoretic variants (Gavrilova and Anisimova, 2014). Data of hybridological analysis suggested that helianthinin subunits are encoded by at least three loci, HelA, HelB and HelC with a number of polymorphic alleles. The HelA locus is inherited independently of the HelB and $\mathrm{HelC}$ loci, and the HelB and $\mathrm{HelC}$ loci are linked with recombination frequency of about $20 \%$ (Anisimova et al., 2004).

Helianthinin of the common sunflower and related wild species $H$. argophyllus Torr. \& A. Gray and H.praecox Engelm. \& A. Gray is characterized by a similar variability pattern (Anisimova et al., 1993). This can serve as an illustration of the universality of the law of homologous (parallel) series in hereditary variability discovered by N. I. Vavilov in 1920. N. I. Vavilov pointed out: "Species and genera that are genetically close to each other are characterized by identical series of hereditary variability with such correctness that, knowing a number of forms for one species, it is possible to predict the presence of identical forms in other species and genera" (Vavilov, 1935). Most of the helianthinin allelic variants typical to the common sunflower are also characteristic of annual wild species H. argophyllus, H.praecox, and H.petiolaris
Nutt. The distinctive marker character of cultivated sunflower helianthinin, the polypeptide variant encoded by the $\mathrm{HelC}_{d}$ allele has not been found in annual ancestors and, therefore, can be considered a domestication-associated character. The relative helianthinin content is much higher in seeds of the cultivated sunflower, particularly in improved varieties and hybrids, than in seeds of wild species; this is undoubtedly associated with the larger sizes of achenes (Anisimova et al., 1993). More significant differences are observed between perennial and annual species, however, in all Helianthus species these proteins have two or three electrophoretic variants that are identical in molecular weight (Anisimova et al., 1993). It is hard to say whether the "domesticated" helianthinin polypeptide variant already existed in natural populations and was randomly selected upon domestication, or if it arose as a result of mutation in the already domesticated forms, especially since the center of origin for the cultivated sunflower is still disputable. Studying helianthinin polymorphism in natural populations of wild $H$.annuus, and sequencing helianthinin-encoding genes in a wide range of genotypes could solve this problem.

Despite the progress in sequencing and annotating the sunflower genome, as well as the practical and biological significance of the character, the genomic organization of helianthinin- coding genes has not yet been studied. In the reference genome of sunflower only the $H a G 3-D$ gene has been localized in linkage group 10 . The gene includes three exons and encodes a precursor consisting of 493 amino acid residues (aa). It was suggested that the sunflower genome contains at least two divergent gene subfamilies of helianthinin-encoding genes, each comprising two or three members (Vander Haar et al., 1988), but to date the products of translation are known only for the $H a G 3-A$ gene, presumably encoding C subunit (Bogue et al., 1988). The sequences of other helianthinin genes and their genomic localization have not yet been determined.

Another important group of proteins that accumulate in sunflower seeds is water-soluble $2 \mathrm{~S}$ albumins. $2 \mathrm{~S}$ albumins of oilseed plants are characterized by a high nutritional value due to the extremely high content of the essential amino acid methionine, as well as protective activity against fungal pathogens. Some $2 \mathrm{~S}$ albumin proteins (sunflower, Brazil nut, castor bean) are highly allergenic due to the presence of conserved IgE-binding epitopes in the molecule. Therefore, in recent years, interest in this protein group as an object for studying nutritional and functional properties, as well as clinical studies, has sharply increased.

In most plants, $2 S$ albumins consist of a large and a small polypeptide chain, which are formed after cleavage of the precursor. In contrast, sunflower $2 \mathrm{~S}$ albumins (molecular weight 10-18 kDa) have a unique structure. 
They exist as single polypeptides bound by intramolecular disulfide bonds (Anisimova et al., 1995). The quantitatively predominant component of the sunflower $2 \mathrm{~S}$ albumin fraction is a unique low molecular weight $(12.133 \mathrm{kDa})$ protein SFA8. It consists of 103 aa and contains 16 methionine and 8 cysteine residues (Kortt et al., 1991).

The SFA 8 gene is located in linkage group 11 of the sunflower reference genome. Two allelic variants of the SFA8 protein were identified which slightly differed in their mobility in the polyacrylamide gel and isoelectric points. The SFA8 level in the $2 S$ albumin fraction in cultivated varieties, especially in hybrids, is higher compared to wild species, which is probably due to domestication effect (Anisimova et al., 2003). The nucleotide and translated amino acid sequences of SFA 8 were found to be polymorphic among the genotypes. Two variants of the SFA8 coding sequence were found in a line in which two protein variants were present, the normal with an isoelectric point (pI) 6.0 ("wild type") and its allelic variant with pI 6.5 ("wild type"). The nucleotide substitution $108 \mathrm{C}-\mathrm{G}$ in one of the sequences resulted in the substitution of the polar uncharged amino acid serine with positively charged arginine, which leads to a change in the charge of the protein and its isoelectric point. The secondary structure of the SFA8 intron variants in the annual wild species $H$.agrophyllus was similar to the cultivated sunflower, but differed from that of the annual H. petiolaris and perennial H.giganteus L. Recently a possible role of the intron in the regulation of translation of SFA8 protein has been demonstrated (Sun et al., 2015). Probably the differences in the intron secondary structure may be important for understanding SFA8 expression pattern, and polymorphism of coding sequences can be useful for elucidating the molecular mechanisms of interspecific and intraspecific differences in the biochemical and functional properties of this valuable protein (Anisimova et al., 2018).

\section{Studies of structural and functional reorganization of the sunflower genome under distant hybridization}

N. I. Vavilov paid special attention to distant (interspecific and intergeneric) hybridization, considering it both a powerful breeding method and an important evolutionary mechanism. Nikolai Ivanovich wrote in 1935: "In the light of the latest cytogenetic findings, the prospects for the practical use of distant hybridization in crop production become extremely significant and attractive. It is very likely that in the coming years we will witness major events in this area." (Vavilov, 1987). N.I. Vavilov considered distant hybridization a tool for transferring resistance to diseases, pests and adverse environmental factors from wild to cultivated species. The sunflower, like many other crop species, has a very narrow genetic basis and therefore is susceptible to many diseases. The task of increasing the immunity of the cultivated sunflower by transferring resistance genes from a highly resistant perennial species H. tuberosus L. (Jerusalem artichoke) was first stated by Soviet researcher N. A. Shchibrya (1938). Studies over the next decades have shown that only wild species of the genus are sources of CMS, $R f$ genes, resistance to pests and unfavorable environmental conditions, original fatty acid composition, and other valuable traits and properties (Christov, 2013). To date, in different countries, valuable breeding material was obtained from hybrids between the cultivated sunflower and wild species. This includes lines resistant to fungal diseases, drought, and other traits introgressed from wild species.

A series of interspecific sunflower hybrid progenies deriving from crosses of a CMS line as the maternal form, and 14 perennial species of various ploidy levels as the male parents, were developed in VIR. The putatively introgressive lines obtained from these crosses differ in phenotypic homogeneity and are characterized by a number of valuable biological characters presumably obtained from the perennial parent - namely, resistance to pathogens, the ability to suppress CMS phenotype, and a peculiar morphotype. Interspecific hybrids showed karyotype stabilization at the diploid level, regardless of the ploidy of the paternal species. In the $\mathrm{F}_{2}$ and subsequent generations, similar morphological types appeared, regardless of perennial parental species (Gavrilova and Anisimova, 2003).

We used seed protein patterns as a marker character for studying the structural and functional reorganization of the sunflower genome during interspecific hybridization. Helianthinin polypeptide composition was identical in the seeds of the maternal line and $F_{1}$ hybrid seeds, however, pattern alterations were observed in subsequent generations. These alterations were similar in different introgressive lines obtained from interspecific hybrids with and without the use of biotechnological methods. Most changes were non-random and associated with the composition of the polypeptides controlled by the HelC locus. The new allelic variants were typical to the related annual wild species $H$. praecox and H. argophyllus. RAPD analysis has revealed instability in the genome of introgressive lines even after long-term inbreeding (in the $\mathrm{F}_{8}-\mathrm{F}_{12}$ generations) (Anisimova et al., 2009).

Interspecific hybridization is known to be a powerful stress, leading to reorganization and destabilization of the genome (effects of "genomic shock", McClintock, 1984). At the phenotypic level, genomic instability is manifested in the variability of morphological characters, deviations from the expected inheritance character; on the cytogenetic level it is expressed in obvious mei- 
otic disturbances. The effects of "genomic shock" under distant hybridization can be largely due to transposon activation. The molecular mechanisms of sunflower genome structural reorganizations during interspecific hybridization in the sunflower are still unknown and may be of interest for genomic and transcriptomic projects.

\section{Search for valuable genes based on the homology principle}

In the new era of genetics the universality of N. I. Vavilov's law of homologous series has been supported by numerous cytogenetic data on homology and homeology of genomes, chromosomes and genes, followed by extensive molecular genetic information on genome synteny, similarity in organization, expression regulation and structure of genes which have identical functions in different organisms. Today, a researcher can identify genes of interest if the position of a homologous gene in the genome of a related species or genus is known. This efficiently works when the genomes of analyzed species and related species or genus are already sequenced and annotated, and when information about the nucleotide sequence of a gene or amino acid sequence of the encoding protein is available.

Restoration of pollen fertility is a meaningful biological and economically valuable character. Cytoplasmic male sterility-restoration of fertility (CMS- $R f$ ) genetic systems are wildly used in hybrid seed production of many important crops such as rice, maize, sorghum, and sunflower. Testing genotypes for the ability to suppress the CMS phenotype is a long process which takes two generations (crossing with a female line and testing $\mathrm{F}_{1}$ hybrids). Therefore, identification of $R f$ gene candidates is of primary importance for developing efficient diagnostic markers for selecting restorer lines. However, the nature of $R f$ genes is poorly investigated in most crops and most fertility restoration genes are identified only based on Mendelian analysis. For example, the Rf1 gene was cloned and sequenced only in sorghum (Klein et al., 2005), whereas no information was available on the nature of $R f$ genes of sunflower and potato.

With only a few exceptions, most of the identified genes for pollen fertility restoration of dicotyledonous and monocotyledonous plants code PPR proteins, which are characterized by canonical tandemly arranged degenerate 35 aa motives (Lurin et al., 2004). The PPR genes are multiple in genomes of higher plants and are represented by hundreds of copies. The PPR genes, the products of which have the function of fertility restoration, are identified as a separate subfamily of $R F L-P P R$ (Restoration of Fertility Like-PPR). The RFL-PPR genes are different from the $P P R$ genes, which do not possess the fertility restoration function in that they have 14-20 PPR motives and are characterized by extensive variability. The $R F L-P P R$ genes are characterized by a high prevalence of nonsynonymous over synonymous amino acid substitutions, and by cluster organization in genomes (Fujii et al., 2011)

Multiple copies of RFL-PPR genes are usually clustered in several genomic loci and probably homologous in different plants. This made it possible to develop the bioinformatic pipeline for in silico identification of $R f$ gene candidates (Sykes et al., 2017).

Polymorphism of the RFL-PPR sequences among the sunflower lines with different abilities to suppress the CMS phenotype was demonstrated (Anisimova et al., 2014). Recently, based on GWAS analysis, $21 R f 1$ candidate genes were identified in a vast region $(7.72 \mathrm{Mb})$ of chromosome 13. Twenty genes belonged to the $P P R$ family and only one coded for aldehyde dehydrogenase (Goryunov et al., 2019).

In sorghum hybrid breeding, the A1 CMS type is predominantly used. With the use of hybridological analysis at least two major $R f$ genes have been identified, $R f 1$ located on chromosome SDI08 (Klein et al., 2005) and $R f 2$ located on the SDI02 chromosome region which is syntenic to the $R f 1$-containing chromosome region of the rice (Oryza sativa L.) genome (Jordan et al., 2010). The dominant and recessive alleles of the $R f 1$ gene were highly polymorphic (Klein et al., 2005). We have designed specific primers based on the reference fragments selected from the database of the sorghum genome. A significant polymorphism of nucleotide sequences was found to be characteristic for the fragment of the $R f 2$ locus (Anisimova et al., 2017). Later this locus was sequenced by Madugula et al. (2018), and sequence polymorphism between sterile and restorer lines was demonstrated.

The comparative genomic approach was also applied in searching for potato (S. tuberosum) $R f$ gene candidates. Based on similarity to the petunia $R f-P P R 592$ gene, 38 fragments were identified in five loci of the whole-genome nucleotide sequence of the potato genome. The putative encoded mitochondrial proteins have a length of 589-597 amino acid residues and, similarly to RF-PPR proteins of the petunia and chili pepper, contain 14 or 15 PPR motives. Primers have been developed which flanked the most variable regions of the selected loci, and polymorphism of the cloned fragments has been investigated in a subset of nine potato genotypes with different cytoplasm type and pollen fertility level. The analyzed genomic fragments possessed characteristic features of the RFL-PPR genes: a high level of polymorphism, a prevalence of nonsynonymous substitutions over synonymous ones, and a high variability of the positions 1, 3 and 6 within the PPR motif. The results demonstrated that the analyzed sequences belonged to the RFL-PPR gene subfamily and might be considered $R f$ gene candidates in the potato (Anisimova et al., 2019). 
Thus, we can conclude that the scientific ideas of N. I. Vavilov have predefined all principal research directions and methodologies of investigations in the field of genetics of cultivated plants for the present time.

\section{Acknowledgement}

This work was performed within the framework of state tasks \#0662-2019-0006 and \#0662-2019-0001.

\section{References}

Abdullaev, R.A., Lebedeva T.V., Alpatieva, N.V., Yakovleva, O.V., Kovaleva, O. N., Radchenko, E. E., Anisimova, I. N., Batasheva, B.A., Karabitsina, Yu. I., and Kuznetsova, E. B. 2019. Genetic diversity of barley accessions from Ethiopia for powdery mildew resistance. Russian Agricultural Sciences 45(3):232-235. https://doi. org/10.3103/S1068367419030029

Abdullaev, R. A., Alpatieva, N. V., Zveinek, I. A., Batasheva, B. A., Anisimova, I. N., and Radchenko, E. E. 2017. Diversity of Dagestan barleys for the duration of the period between shooting and earing stages and alleles in the Ppd-H1 and Ppd-H2 loci. Russian Agricultural Science 43(2):99-103. https://doi.org/10.3103/S1068367417020021

Anisimova, I. N. and Gavrilyuk, I. P. 1989. Heterogenety and polymorphism of $11 \mathrm{~S}$ globulin in sunflower seeds. Soviet Genetics 25(7):1215-1233. (In Russian)

Anisimova, I. N., Georgieva-Todorova, J., and Vassileva, R. 1993. Variability of the major seed globulin in the genus Helianthus L. Helia 16(18):49-58.

Anisimova, I. N., Fido, R. J., Tatham, A.S., and Shewry, P.R. 1995. Genotypic variation and polymorphism of $2 \mathrm{~S}$ albumins of sunflower. Euphytica 83:15-23. https://doi. org/10.1007/BF01677856

Anisimova, I. N., Konarev, Al. V., Gavrilova, V.A., Fido, R. F., Thatam, A.S., and Shewry, P.R. 2003. Polymorphism and inheritance of methionine-rich 25 albumins in sunflower. Euphytica 129(1):99-107. https://doi. org/10.1023/A:1021562712945

Anisimova, I. N., Gavrilova, V.A., Rozhkova, V.T., Loskutov, A. V., and Tolmachev, V.V. 2004. Polymorphism and inheritance of seed storage proteins in sunflower. Russian Journal of Genetics 40(9):995-1002. https://doi. org/10.1023/B:RUGE. 0000041378.51180.0b

Anisimova, I. N., Tumanova, L. G., Gavrilova, V.A., Dyagileva, A. V., Pasha, L. I., Mitin, V. A., and Timofeyeva, G. I. 2009. Genomic instability in sunflower interspecific hybrids. Russian Journal of Genetics 45(8):934-943. https:// doi.org/10.1134/S1022795409080079

Anisimova, I. N., Gavrilova, V.A., Rozhkova, V.T., Port, A. I., Timofeeva, G. I., and Duka, M. V. 2011. Genetic diversity of sources of sunflower pollen fertility restorer genes. Russian Agricultural Sciences 37:192. https://doi. org/10.3103/S1068367411030025

Anisimova, I. N., Alpatieva, N. V., Rozhkova, V.T., Kuznetsova, E. B., Pinaev, A. G., and Gavrilova, V. A. 2014. Polymorphism among RFL-PPR homologs in sunflower (Helianthus annuus L.) lines with varying ability for the suppression of the cytoplasmic male sterility phenotype. Russian Journal of Genetics 50(7):712-721. https://doi. org/10.1134/S1022795414070023

Anisimova, I. N., Alpatieva, N. V., Goryunova, S. V., Goryunov, D. V., Konarev, Al. V., Gavrilova, V. A., and Radchenko, E. E. 2018. Structural variability of sunflower gene for methionine-rich albumin SFA8. Proceedings of Applied Botany, Genetics and Breeding 179(4):91-103. https://doi. org/10.30901/2227-8834-2018-4-91-103
Anisimova, I. N., Alpatieva, N. V., Karabitsina, Y. I., and Gavrilenko, T.A. 2019. Nucleotide sequence polymorphism in the RFL-PPR genes of potato. Journal of Genetics 98:87. https://doi.org/10.1007/s12041-019-1130-1

Baute, G. J., Kane, N. C., Grassa, C. J., Lai, Z., and Rieseberg, L. H. 2015. Genome scans reveal candidate domestication and improvement genes in cultivated sunflower, as well as post-domestication introgression with wild relatives. New Phytologist 206:830-838. https://doi.org/10.1111/ nph.13255

Bogue, M. A., Vonder Haar, R. A., Nuccio, M., Griffing, L. R., and Thomas, T. L. 1990. Developmentally regulated expression of a sunflower $11 \mathrm{~S}$ seed protein gene in transgenic tobacco. Molecular and General Genetics 222(1):49-57. https://doi.org/10.1007/BF00283022

Chapman, V. A., Pashley, C. H., Wenzler, J., Hvala, J., Tang, S., Knapp, S. J., and Burke, J. M. 2018. A genomic scan for selection reveals candidates for genes involved in the evolution of cultivated sunflower (Helianthus annuus). The Plant Cell 20:2931-2945. https://doi.org/10.1105/ tpc. 108.059808

Christov, M. 2013. Contribution of interspecific and intergeneric hybridization to sunflower breeding. Helia 36(58):1-18. https://doi.org/10.2298/HEL1358001A

Cockerham, G. 1970. Genetical studies on resistance to potato viruses $X$ and Y. Heredity 25(3):309-348. https://doi. org/10.1038/hdy.1970.35

Flor, H. H. 1971. Current status of the gene-for-gene concept. Annual Review of Phytopathology 9:275-296. https://doi. org/10.1146/annurev.py.09.090171.001423

Fry, W. E., Goodwin, S. B., Matuszak, J. M., Spielman, L. J., Milgroom, M. G., and Drenth, A. 1992. Population genetics and intercontinental migrations of Phytopthora infestans. Annual Review of Phytopathology 30:107-129. https://doi. org/10.1146/annurev.py.30.090192.000543

Fujii, S., Bond, Ch. S., and Small, I. D. 2011. Selection patterns on restorer-like genes reveals a conflict between nuclear and mitochondrial genomes throughout angiosperm evolution. Proceedings of the National Academy of Sciences USA 108(4):1723-1728. https://doi.org/10.1073/ pnas. 1007667108

Gavrilova, V. A. and Anisimova, I. N. 2003. Genetics of cultivated plants. St. Petersburg, VIR. 186 p. (In Russian)

Gavrilova, V. A., Rozhkova, V. T., and Anisimova, I. N. 2014. Sunflower genetic collection at the Vavilov Institute of Plant Industry. Helia 37(60):1-16. https://doi.org/10.1515/helia-2014-0001

Gavrilova, V.A. and Anisimova, I. N. 2017. Genealogy of the sunflower lines created on the basis of Russian varieties. Helia 40(67):133-146. https://doi.org/10.1515/helia-2017-0025

Goncharov, N. 2013. Domestication of plants. Vavilov Journal of Genetics and Breeding 17(4/2):884-899. (In Russian)

Goryunov, D. V., Anisimova, I. N., Gavrilova, V.A., Chernova, A. I., Sotnikova, E. A., Martynova, E. U., Boldyrev, S. V., Ayupova, A. F., Gubaev, R. F., Mazin. P.V., Gurchenko, E. A., et al., Shumskiy, A. A., Petrova, D. A., Garkusha, S. V., Mukhina, Z. M., Benko, N. I., Demurin, Y. N., Khaitovich, P. E., and Goryunova, S. V. 2019. Association mapping of fertility restorer gene for CMS PET1 in sunflower. Agronomy 9(2):49. https://doi.org/10.3390/agronomy 9020049

Jordan, D. R., Mace, E.S., Henzell, R. G., Klein, P. E., and Klein, R. R. 2010. Molecular mapping and candidate gene identification of the $R f 2$ gene for pollen fertility restoration in sorghum [Sorghum bicolor (L.) Moench]. Theoretical and Applied Genetics 120(7):1279-1287. https://doi. org/10.1007/s00122-009-1255-3 
Klein, R. R., Klein, P. E., Mullet, J. E., Minx, P., Rooney, W. L., and Schertz K. F. 2005. Fertility restorer locus $R f 1$ of sorghum (Sorghum bicolor L.) encodes a pentatricopeptide repeat protein not present in the collinear region of rice chromosome 12. Theoretical and Applied Genetics 111(6):9941012. https://doi.org/10.1007/s00122-005-2011-y

Kolesova, M. A. and Tyryshkin, L. G. 2018. Inheritance of effective juvenile leaf rust resistance in six accessions of Aegilops speltoides Tausch. Proceedings on Applied Botany, Genetics and Breeding 179(4):105-110. https://doi. org/10.30901/2227-8834-2018-4-104-110 (In Russian)

Konarev, A. V. 2006. Utilization of molecular markers in solving problems of plant genetic resources and breeding. Agrarian Russia 6:4-22. (In Russian)

Kortt, A. A., Caldwell, J. B., Lilley, G. G., Higgins, T.J. V. 1991. Amino acid CDNA sequences of a methionine-rich $2 \mathrm{~S}$ protein from sunflower seed (Helianthus annuus L.). European Journal of Biochemistry 195(2):329-334. https:// doi.org/10.1111/j.1432-1033.1991.tb15710.x

Lebedeva, T. V. and Peusha, H. O. 2006. Genetic control of the wheat Triticum monococcum L. resistance to powdery mildew. Russian Journal of Genetics 42(1):60-66. https:// doi.org/10.1134/S102279540601008X

Lurin, C., Andres, C., Aubourg, S., Bellaoui, M., Bitton, F., Bruyere, C., Caboche, M., Debast, C., Gualberto, J., Hoffmann, B., Lecharny, A., Le Ret, M., Martin-Magniette, M. L., Mireau, H., Peeters, N., Renou, J.P., Szurek, B., Taconnat, L., and Small I. 2004. Genome-wide analysis of Arabidopsis pentatricopeptide repeat proteins reveals their essential role in organelle biogenesis. Plant Cell 16(8):20892103. https://doi.org/10.1105/tpc.104.022236

Madugula, P., Uttam, A. G., Tonapi, V. A., and Ragimasalawada, M. 2018. Fine mapping of $R f 2$, a major locus controlling pollen fertility restoration in sorghum $A_{1}$ cytoplasm, encodes a PPR gene and its validation through expression analysis. Plant Breeding 137(2):148-161. https://doi. org/10.1111/pbr.12569

Mandel, J. R., McAssey, E. V., Nambeesan, S., Garcia-Navarro, and E., Burke, J. M. 2014. Molecular evolution of candidate genes for crop-related traits in sunflower (Helianthus annuus L.). PLOS ONE 9(6):e99620. https://doi. org/10.1371/journal.pone.0099620

Mc Clintock, B. 1984. The significance of responses of the genome to challenge. Science 226(4676):792-801. https:// doi.org/10.1126/science.15739260

Megías, C., Pedroche, J., Yust, M. D. M., Alaiz, M., Girón-Calle, J., Millán, F., and Vioque, J. 2009. Stability of sunflower protein hydrolysates in simulated gastric and intestinal fluids and Caco-2 cell extracts. LWT - Food Science and Technology 42(9):1496-1500. https://doi.org/10.1016/j. Iwt.2009.04.008

Munoz, F. J., Plaisted, R. L., and Thurston, H. D. 1975. Resistance to potato virus $Y$ in Solanum tuberosum spp. andigena. American Potato Journal 52(4):107-115. https://doi. org/10.1007/BF02852043

Radanović, A., Miladinović, D., Cvejić, S., Jocković, M., and Jocić, S. 2018. Sunflower genetics from ancestors to modern hybrids - A Review. Genes 9:528. https://doi. org/10.3390/genes9110528

Radchenko, E.E. 2011. Resistance of Triticum species to cereal aphids. Czech Journal of Genetics and Plant Breeding 47(Special issue):67-70. https://doi. org/10.3390/10.17221/3257-CJGPB

Radchenko, E. E. 2000. Identification of genes for resistance to greenbug in sorghum. Russian Journal of Genetics 36(4):408-417.

Radchenko, E. E. 2006. Inheritance of greenbug resistance in several forms of grain sorghum and sudangrass. Russian
Journal of Genetics 42(1):55-59. https://doi.org/10.1134/ S1022795406010078

Radchenko, E. E., Kuznetsova, T.L., Chumakov, M. A., and Loskutov, I. G. 2018. Greenbug (Schizaphis graminum) resistance in oat (Avena spp.) landraces from Asia. Genetic Resources and Crop Evolution 65(2):571-576. https://doi. org/10.1007/s10722-017-0554-9

Radchenko, E. E., Kuznetsova, T. L., Zveinek, I. A., and Kovaleva, O. N. 2014. Greenbug resistance in barley accessions from East and South Asia. Russian Agricultural Science 40(2):117-120. https://doi.org/10.3103/ S1068367414020177

Radchenko, E. E. and Tyryshkin, L. G. 2004. Components of the greenbug (Schizaphis graminum Rond.) resistance in wheat and barley somaclonal variants. Cereal Research Communications 32(2):255-258.

Radchenko, E. E. and Zubov, A. A. 2007. Genetic diversity of sorghum in greenbug resistance. Russian Agricultural Science 33(4):223-225. https://doi.org/10.3103/ S1068367407040039

Rigin, B. V. 2006. Trofim Yakovlevich Zarubailo and genetics in the N. I. Vavilov All-Russian Institute of Plant Industry (to the 100 th birthday). VOGIS Herald 10(3):594-601. (In Russian)

Rigin, B. V. and Yakovleva, O. V. 2006. Genetic analysis of toxic aluminium ion tolerance in barley. Russian Journal of Genetics 42(3):301-305. https://doi.org/10.1134/ S1022795406030100

Rigin, B. V., Zuev, E. V., Tyunin, V. A., Shreider, E. R., Pyzhenkova, Z.S., and Matvienko, I. I. 2018. Breeding and genetic aspects of creating productive forms of fast-developing spring bread wheat. Proceedings on Applied Botany, Genetics and Breeding 179(3):194-202. https://doi. org/10.30901/2227-8834-2018-3-194-202 (In Russian)

Shchibrya, N. A. 1938. Crossing Jerusalem artichoke (Helianthus tuberosus L.) with sunflower (Helianthus annuus L.) Proceedings of the USSR Academy of Sciences 11(5):189192. (In Russian)

Shaposhnikov, G. Kh. 1967. Evolution of aphids related with specialization and change of the hosts. Extended Abstract of Doctor of Science Dissertation. Leningrad. $41 \mathrm{p}$. (In Russian)

Shewry, P. R., Napier, J. A., and Thatam, A. 1995. Seed storage proteins: structures and biosynthesis. The Plant Cell 7(7):945-956. https://doi.org/10.1105/tpc.7.7.945

Solodukhina, O.V. 2002. Genetic characterization of rye accessions with regard to leaf rust resistance. Russian Journal of Genetics 38(4):399-407. https://doi. org/10.1023/A:1015202303392

Solodukhina, O. V. 2003. The genetic basis of breeding winter rye for resistance to rust and powdery mildiew. Extended Abstract of Doctor of Science Dissertation. St. Petersburg. 36 p. (In Russian)

Sun, J., Hao, H. Z., Nie, L., Yi, J., and Zang, Q.-L. 2015. The intron in an albumin gene from sunflower increases expression of SFA8. In: H. Budak, G. Spangenberg (eds.) Molecular Breeding of Forage and Turf, pp. 183-191. https:// doi.org/10.1007/978-3-319-08714-6_16

Sykes, T., Yates, S., Nagy, I., Asp T., Small, I., and Studer, B. 2017. In silico identification of candidate genes for fertility restoration in cytoplasmic male sterile perennial ryegrass (Lolium perenne L.). Genome Biology and Evolution 9(2):351-362. https://doi.org/10.1093/gbe/evw047

Tyryshkin, L. G. and Shevchenko, D. N. 1994. Somaclonal variation of barley to diseases resistance. Plant Science 31(7-10):166-168.

Tyryshkin, L. G., Gultyaeva, E. I., Aplpatieva, N. V., and Kramer, I. 2006. Identification of effective leaf rust resistance 
genes in wheat (Triticum aestivum) using STS markers. Russian Journal of Genetics 42(6):662-666. https://doi. org/10.1134/S1022795406060111

Tyryshkin, L. G. 2007. The genetic diversity of wheat and barley by effective disease resistance and the possibility of its broadening. Extended Abstract of Doctor of Science Dissertation. St. Petersburg. 40 p. (In Russian)

Vonder Haar, R. A., Allen, R. D., Cohen, E. A., Nessler, C. L., and Thomas, T. L. 1988. Organization of the sunflower $11 \mathrm{~S}$ storage protein gene family. Gene 74(2):433-443. https://doi.org/10.1016/0378-1119(88)90176-X

Vavilov, N.I. 1913. The facts about the resistance of bread cereals to parasitic fungi. Trudy selektsionnoy stantsii pri Moskovskov selskokhoziaistvennom institute 1:1-110. (In Russian)

Vavilov, N. I. 1935. The law of homologous series in hereditary variability. Theoretical Foundations of Plant Breeding. General Plant Breeding. V. 1, pp. 75-128. (In Russian)

Vavilov, N. I. 1964. Laws of Natural Immunity of Plants to Infectious Diseases. Keys to Finding Immune Forms. Se- lected Works. Vol. 4. Moscow-Leningrad, pp. 430-488. (In Russian)

Vavilov, N. I. 1987. Theoretical Bases of Breeding. M.: Nauka, 1987, 511 p. (In Russian)

Yakovleva, O. V. 2018. Phytotoxicity of aluminum ions. Proceedings on applied botany, genetics and breeding 179(3):315331. https://doi.org/10.30901/2227-8834-2018-3-315-331

Zoteyeva, N., Chrzanowska, M., Flis, B., and Zimnoch-Guzowska, E. 2012. Resistance to pathogens of the potato accessions from the collection of N. I. Vavilov Institute of Plant Industry (VIR). American Journal of Potato Research 89(4):277-293. https://doi.org/10.1007/s12230012-9252-5

Zoteyeva, N., Mezaka, I., Vilcâne, D., Carlson-Nilsson, U., Skrabule, I., and Rostoks, N. 2014. Assessment of genes $R 1$ and $R 3$ conferring resistance to late blight and of gene $R y_{\text {sto }}$ conferring resistance to Potato Virus Y in two wild species accessions and their hybrid progenies. Proceedings of the Latvian Academy of Sciences, Section B 68(3/4):133141. https://doi.org/10.2478/prolas-2014-0015 